Article

\title{
Biomass and Nutrients Variation of Chinese Fir Rooted Cuttings under Conventional and Exponential Fertilization Regimes of Nitrogen
}

\author{
Jiasen Wu ${ }^{1}$, Haiping Lin ${ }^{1}$, Lianhua Guo ${ }^{2}$, Jiaqi Dong ${ }^{2}$, Luyao Zhang ${ }^{2}$ and Weijun Fu 1,3,*(D) \\ 1 State Key Laboratory of Subtropical Silviculture, Zhejiang A \& F University, Lin'an 311300, China \\ 2 School of Environmental and Resources Science, Zhejiang A\&F University, Lin'an 311300, China \\ 3 Zhejiang Provincial Key Laboratory of Carbon Cycling in Forest Ecosystems and Carbon Sequestration, \\ Zhejiang A\&F University, Lin'an 311300, China \\ * Correspondence: fuweijun@zafu.edu.cn; Tel.: +86-571-6108-1397
}

Received: 11 June 2019; Accepted: 21 July 2019; Published: 25 July 2019

\begin{abstract}
Exponential fertilization has been regarded as an important technique for improving seedling quality at the initial plant-growth stage. In our study, containerized one-year-old Chinese fir (Cunninghamia lanceolata (Lamb.) Hook) rooted cuttings were reared at four nitrogen $(\mathrm{N})$ fertilizer levels $\left(0,0.5,1.0,2.0 \mathrm{~g}_{\text {cutting }}{ }^{-1}\right.$ season $^{-1}$ ) under two topdressing methods (conventional and exponential) for a 210-day greenhouse rotation to evaluate growth and nutrient loading capacity of seedlings. $\mathrm{N}$ fertilizer was applied 20 times at an interval of 10 days during the study period. The results indicated that the schedule and rate of fertilization significantly affected the height, ground diameter, and biomass of Chinese fir rooted cuttings. The nitrogen concentration of different plant organs followed the order of leaves $>$ root $>$ stem. Compared to the $\mathrm{CK}$, the $\mathrm{N}$ concentrations in root, stem, and leaves increased by $39.6 \%, 16.6 \%$, and $41.1 \%$ in the conventional fertilizer treatment, and by $22.6 \%$ to $81.4 \%, 27.3 \%$ to $152.6 \%$, and $73.6 \%$ to $135.5 \%$ in exponential fertilization treatments, respectively. The $\mathrm{N}$ concentrations of root, stem, and leaves of Chinese fir rooted cuttings under EF2 $\left(1.0 \mathrm{~N} \mathrm{~g}_{\text {cutting }}{ }^{-1}\right)$ were significantly higher than that of conventional fertilization $(p<0.05)$. However, there was no significant difference of phosphorus and potassium concentrations among different plant organs. Steady-state nutrition and superior growth performance were achieved by rooted cuttings fertilized exponentially at the rate of $1.0 \mathrm{~g} \mathrm{cutting}^{-1}$ yielding (EF2).
\end{abstract}

Keywords: Chinese fir rooted cuttings; exponential fertilization; chlorophyll fluorescence; nitrogen

\section{Introduction}

The quality of seedlings is one of the most important factors for maximizing post-planting tree seedling survival and growth during the early stage of plantation establishment [1,2]. Non-target vegetation competes with target-tree species for nutrients, water, and light, which could significantly decrease tree seedling survival [3]. Previously, herbicides was applied to alleviate vegetation competition. However, an increasing public concern is accompanying such vegetation management due to the environmental risk caused by the use of herbicides [4]. An alternative approach of planting "nutrient-loaded" seedlings has been regarded as a sustainable vegetation management practice [5]. Therefore, fertilizer application plays an important role in improving the quality of seedlings and further provide a competitive advantage of seedlings over the competing plants after planting [6]. Nitrogen $(\mathrm{N})$ is an essential element for plant growth as a key component in amino acid and protein. Appropriate application of $\mathrm{N}$ fertilizer can promote plant growth, while excessive application can cause non-point source pollution. 
Conventional fertilization measure provides fertilizer at a constant rate during the growth period, which could cause the toxicity of small seedlings and result in excessive nutrient loss if the applied nutrients are not fully absorbed by seedlings at the nursery stage [2,7]. Meanwhile, it can also lead to nutrient deficiency in the late growth stages [8]. The theory of steady-state nutrition, characterized by an increasing nutrient concentration in seedlings, is carried out through delivering nutrients at an exponential rate during nursery production [9]. Exponential fertilization regimes can induce abundant uptake and lead to more nutrient reserves for new tissue growth. Therefore, the steady-state mineral nutrients of the plants are induced, the nutrient load in the seedlings is effectively increased, and the competitiveness of the seedlings is enhanced, so that it can better adapt to the site conditions of the afforestation sites [10-12]. Compared with conventional fertilization, the survival rate of seedlings cultivated by exponential fertilization is higher and the growth effect is better [13]. It is widely used in the European and American afforestation tree species mainly based on Taxodiaceae Warming and Pinaceae Lindl. [14-19]. Since the introduction of steady-state nutrient theory and related technologies in China, we have studied the broad-leaved tree species such as Paulownia elongata S. Y. Hu and Robinia pseudoacacia Linn. [20-23], but there are few studies on the cultivation of fast-growing and high-yield seedlings.

Chinese fir (Cunninghamia lanceolata (Lamb.) Hook) belongs to Cunninghamia $\mathrm{R}$. Br. It is a unique afforestation tree species in southern China, which is characterized by a fast-growing speed and a high-yield wood output. In southern China, the reclamation of disturbed lands has being ongoing since the 1980s. During this process, the rooted cuttings (phenotypical variation among seedlings are very small that they look like the clone) of Chinese fir is generally applied since the 1990s, due to its minor differences among individuals and uniform management of Chinese fir plantations, which can lead to approximately 58.7\% higher output of above-ground biomass [24]. Therefore, the high quality seedlings are the basis for the successful construction of Chinese fir plantations. Xu et al. [25] reported that exponential fertilization effectively promotes the growth of Chinese fir seedlings and improves the nutritional status of seedlings. However, at present the effect of exponential fertilization on rooted cuttings of Chinese fir is still unclear. We hypothesized that the exponential fertilization could improve the growth and the nutrients in organs of Chinese fir rooted cuttings. To study this, a pot experiment was carried out using one-year-old rooted cuttings of Chinese fir under different $\mathrm{N}$ application methods and dosages, which could provide a rational $\mathrm{N}$ fertilizer application strategy for the nutrient management of rooted cuttings of Chinese fir.

\section{Materials and Methods}

\subsection{Study Area}

The study site is located in the greenhouse of the Experimental Base of Zhejiang A\&F University in Lin'an City, Zhejiang Province $\left(30^{\circ} 16^{\prime} \mathrm{N}, 119^{\circ} 44^{\prime} \mathrm{E}\right)$. Lin'an has a subtropical monsoon climate with an annual average temperature of $16.6^{\circ} \mathrm{C}$, ranging from $-13.2{ }^{\circ} \mathrm{C}$ to $41.6{ }^{\circ} \mathrm{C}$. The annual average precipitation is $1628.6 \mathrm{~mm}$. The annual daylight hours and frost-free days are $1774 \mathrm{~h}$ and $235 \mathrm{~d}$, respectively $[25,26]$. The temperature in the greenhouse ranged from 23 to $33^{\circ} \mathrm{C}$ during the experimental period (March 2014 to October 2014), with relative humidity of 55\%-75\%.

\subsection{Experimental Design and N Fertilization Regimes}

The rooted cuttings named "Kai $4 \times \mathrm{Na} 11$ " (from one tree which is a cross between one tree called "Kai 4" and another tree called "Na 11") were from national forestry farmland of Kaihua County, Zhejiang Province. A total of 300 one-year-old Chinese fir rooted cuttings (heights: $25.50 \pm 0.30 \mathrm{~cm}$ and ground diameters: $3.12 \pm 0.05 \mathrm{~mm}$ ) were selected. On 1 March 2014, a plastic pot of $23 \mathrm{~cm} \times 24 \mathrm{~cm} \times 28 \mathrm{~cm}$ (bottom diameter $\times$ upper diameter $\times$ height) was used and one clonal seedling was planted in each pot. The test soil was derived from granite and classified as Ferralsols in the Food and Agriculture Organization (FAO) soil classification system [27]. The basic soil physico-chemical properties were 
determined (pH: 6.6, organic carbon: $4.8 \mathrm{~g} \mathrm{~kg}^{-1}$, alkaline nitrogen: $22.7 \mathrm{mg} \mathrm{kg}^{-1}$, available phosphorus: $0.9 \mathrm{mg} \mathrm{kg}^{-1}$, available potassium: $55.5 \mathrm{mg} \mathrm{kg}^{-1}$ ).

Each pot was filled with $10 \mathrm{~kg}$ of soil and was placed on a plastic tray to collect and reuse the penetrating water with nutrients contained. The pot experiment was carried out in a completely randomized design with 5 levels of fertilizer: Control (CK), conventional fertilization (CF), and exponential fertilization (EF1, EF2, EF3, respectively). The totally seasonal amount of $\mathrm{N}$ applied was $0,0.5,0.5,1.0,2.0 \mathrm{~g}_{\text {cuttling }}{ }^{-1}$, respectively. There were 60 rooted cuttings per level of fertilizer to guarantee the enough lively rooted cuttings at the final harvest stage. During the growth process, the first fertilization was carried out on 21 March 2014. Since then, the $\mathrm{N}$ fertilizer was applied once for every 10 days, giving a total of 20 times fertilization. The conventional fertilization delivered $\mathrm{N}$ at a constant rate of $25 \mathrm{mg}$ seedling ${ }^{-1}$ per 10 days, while the exponential fertilization delivered $\mathrm{N}$ following the exponential fertilization model [28]:

$$
\begin{gathered}
\mathrm{N}_{t}=\mathrm{N}_{s}\left(e^{r t}-1\right)-\mathrm{N}_{t-1}, \\
\mathrm{~N}_{T}=\mathrm{N}_{s}\left(e^{r t}-1\right),
\end{gathered}
$$

where $\mathrm{N}_{t}$ is the $t^{\text {th }} \mathrm{N}$ application amount according to $\mathrm{N}$ addition rate $(\mathrm{r}), \mathrm{N}_{s}$ is the initial $\mathrm{N}$ content of the rooted cuttings, $\mathrm{N}_{t-1}$ is the total $\mathrm{N}$ application at the $(t-1)^{\text {th }}$ fertilization, and $\mathrm{N}_{T}$ is the total $\mathrm{N}$ content of seedlings after the $t^{\text {th }}$ nitrogen application (under fertilizer efficiency of $100 \%$ ). The initial $\mathrm{N}$ content of Chinese fir cuttings is $72.19 \mathrm{mg}$ cutting $^{-1}$. The $\mathrm{N}$ fertilizer is urea, and the specific fertilization progress is shown in Figure 1.

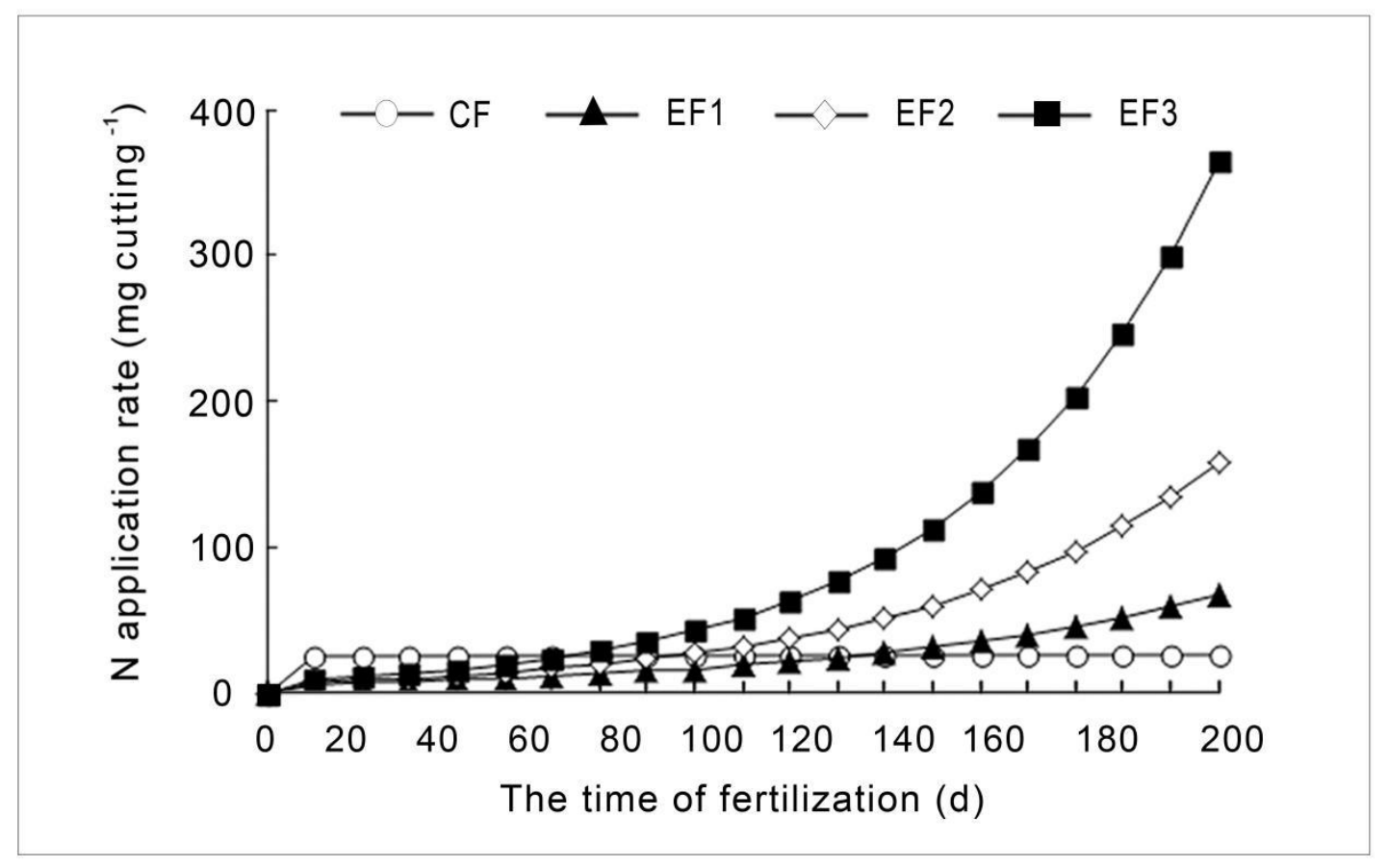

Figure 1. Fertilization at different application levels.

Both superphosphate $\left(7.0 \mathrm{~g}\right.$ cutting $\left.^{-1}\right)$ and potassium sulfate $\left(2.0 \mathrm{~g} \mathrm{cutting}^{-1}\right)$ were applied as base fertilizer at the first fertilization on 21 March 2014. Superphosphate and potassium sulfate were applied into a ring groove (2-cm depth) around the cutting root. The urea was dissolved in water according to different usage, and then equally watered by a cylinder for the same treatment. 


\subsection{Plant Sampling and Chemical Analysis}

\subsubsection{Determination of Chlorophyll Fluorescence Parameters}

After 210 days of fertilization, the chlorophyll fluorescence parameters were carried out using a portable chlorophyll fluorescence meter (PAM-2100, Walz, Germany) on 22 October (a sunny day) from 9:00 to 14:00. The mature leaves at the middle and upper parts of Chinese fir (5 leaves per plant) were selected, and 5 rooted cuttings were randomly selected for each treatment. After dark adaptation for $20 \mathrm{~min}$, the chlorophyll fluorescence parameters were determined. The values of each parameter were automatically generated by the system under the selected mode.

\subsubsection{Biomass Determination}

After the chlorophyll fluorescence parameters were measured, 5 strains of different treated cuttings were harvested, and the whole plant was harvested as a sample. The root-collar diameter and shoot height were measured with a vernier caliper and a flexible rule. The whole plant was washed with fresh water and then rinsed with deionized water. Their roots, stems, and leaves were obtained, respectively. These samples were oven-dried at $105^{\circ} \mathrm{C}$ for $30 \mathrm{~min}$, then at $70^{\circ} \mathrm{C}$ to constant weight.

$$
\text { Total biomass }\left(\mathrm{g} \text { cutting }^{-1}\right)=\text { root biomass }+ \text { stem biomass }+ \text { leaf biomass }
$$

\subsubsection{Determination of Plant Nutrients}

The weighed sample was pulverized through a $0.5 \mathrm{~mm}$ sieve, and the $\mathrm{N}$ content was measured using an elemental analyzer (Elementer, VARIO Macro, Germany). After the sieved sample was dehydrated by $\mathrm{H}_{2} \mathrm{SO}_{4}-\mathrm{H}_{2} \mathrm{O}_{2}$, the potassium $(\mathrm{K})$ content was measured by flame photometer, and the phosphorus $(\mathrm{P})$ content was measured by molybdenum blue colorimetric-spectrophotometry.

\subsection{Data Processing}

The data are presented as average \pm standard deviation (SD). Statistical differences were tested using analysis of variance (ANOVA) for the completely randomized design and Duncan's multiple comparison test in SPSS version 19.0 (IBM, Armonk, NY, USA) [29]. The ANOVA analysis indicated a significant difference, the Duncan's multiple comparison test was used to separate the means. An alpha level of 0.05 for significance was used in all statistical analyses. Before performing the ANOVA analysis, the normality and homogeneity of raw data were tested, and data were log-transformed if the homogeneity of the variance was not met [30-33]. The statistical graphs were produced by Origin 8 and the Excel 2003 software (Microsoft, Redmond, WA, USA).

\section{Results}

\subsection{Effects of Different Fertilization Levels on the Height and Ground Diameter of Chinese Fir Rooted Cuttings}

Compared with the $\mathrm{CK}$, the rooted cuttings' height and the ground diameter of the four $\mathrm{N}$-fertilization treatments significantly increased by $34.1 \%-60.5 \%$ and $20.5 \%-40.4 \%$, respectively (Figure 2). Compared with $\mathrm{CF}$, the cutting heights and ground diameters of exponential fertilization treatments (EF1, EF2, and EF3) increased by $4.1 \%-19.8 \%$ and $4.6 \%-19.8 \%$, respectively. The largest height and ground diameter was found under EF2. 


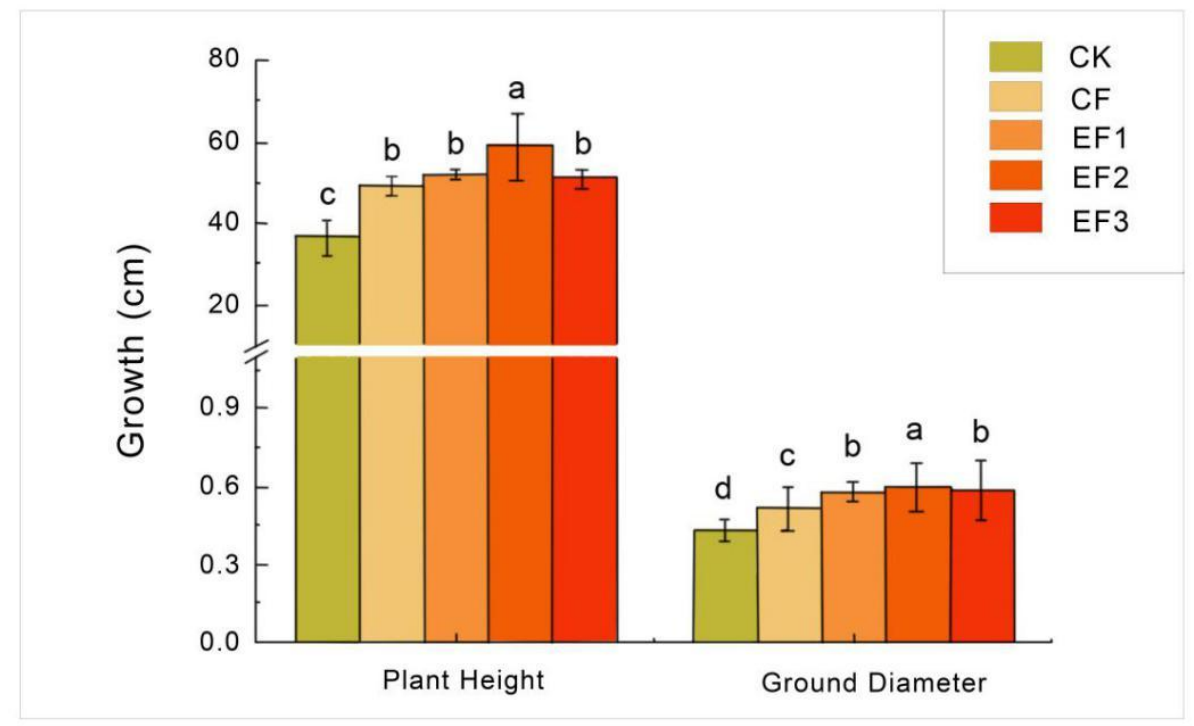

Figure 2. Plant height and ground diameter of Chinese fir cuttings at different fertilization levels. Different letters indicate significant differences between treatments $(p<0.05)$. CK: Control; CF: Conventional Fertilization; EF1: Exponential Fertilization $1\left(0.5\right.$ nitrogen $\left.(\mathrm{N}) \mathrm{g} \mathrm{cuttling}^{-1}\right)$; EF2: Exponential Fertilization $2\left(1.0 \mathrm{~N} \mathrm{~g}_{\text {cutting }}{ }^{-1}\right)$; EF3: Exponential Fertilization $3\left(2.0 \mathrm{~N} \mathrm{~g} \mathrm{cutting}^{-1}\right)$.

\subsection{Effects of Different Fertilization Treatments on the Biomass of Chinese Fir Seedlings}

As shown in Figure 3, the biomass of Chinese fir roots ranged from 10.14 to 14.13 g cutting $^{-1}$, and the differences among the treatments were not significant $(p>0.05)$. Compared with the control, the biomass of stems, leaves, and whole plants of the four $\mathrm{N}$-fertilization levels increased significantly by $113.9 \%-166.9 \%, 158.0 \%-230.9 \%$, and $96.4 \%-128.9 \%$, respectively. Among them, the highest biomass of stem, leaf, and whole plant was found at EF2. Furthermore, the ratios of aboveground biomass and belowground biomass under the four $\mathrm{N}$-fertilization levels were significantly higher than the control (Table 1).

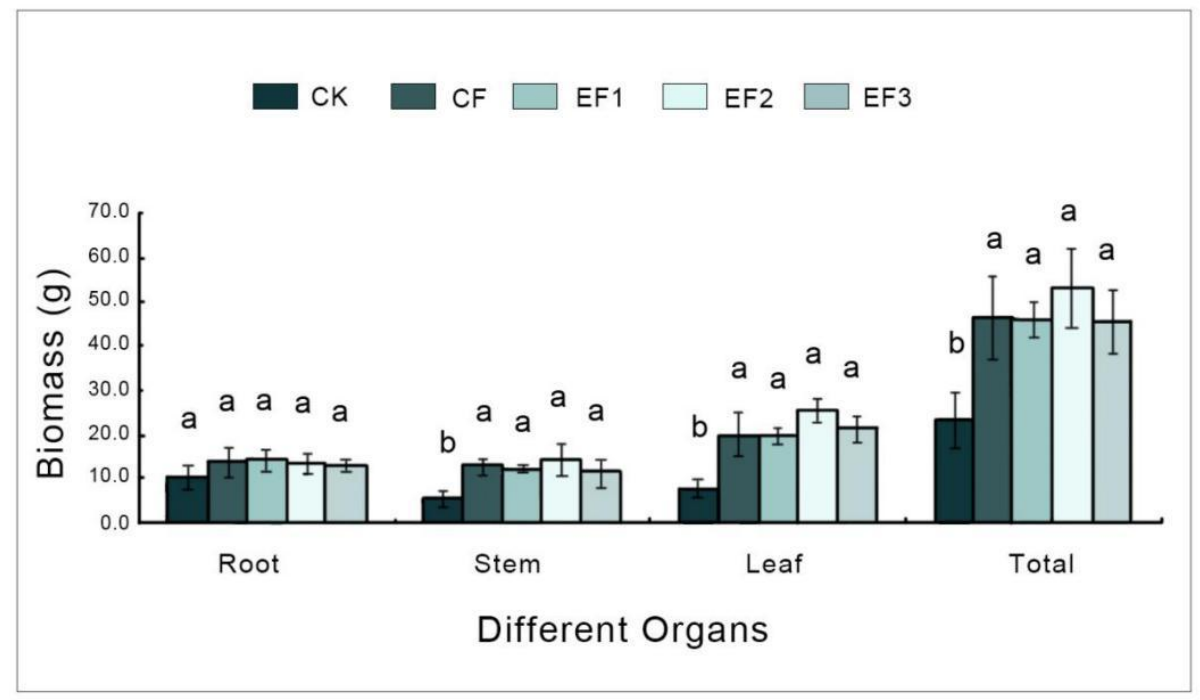

Figure 3. Organ biomass of Chinese fir rooted cuttings influenced by different fertilization levels (Different letters in the same histogram indicate significant difference at 0.05 level). 
Table 1. Ratio of aboveground biomass and belowground biomass under different fertilization levels.

\begin{tabular}{cccccc}
\hline & CK & CF & EF1 & EF2 & EF3 \\
\hline $\begin{array}{c}\text { Aboveground } \\
\text { biomass/Belowground } \\
\text { biomass }\end{array}$ & $0.76 \pm 0.05 \mathrm{c}$ & $1.44 \pm 0.11 \mathrm{~b}$ & $1.40 \pm 0.12 \mathrm{~b}$ & $1.90 \pm 0.17 \mathrm{a}$ & $1.67 \pm 0.13 \mathrm{ab}$ \\
\hline
\end{tabular}

Different letters in the same row indicate significant difference at 0.05 level.

\subsection{Effects of Different Fertilization on the Characteristics of Chlorophyll Fluorescence Parameters of Chinese} Fir Seedlings

The results (Table 2) of photochemical quenching coefficient $\left(Q_{P}\right)$, apparent electron transport rate (ETR), and effective quantum yield of PSII (Yield) of the leaves of Chinese fir seedlings at the exponential fertilization levels, were significantly higher than that of $\mathrm{CF}$ and $\mathrm{CK}$, respectively. When the $\mathrm{N}$ exponential fertilization amount reached $1.0 \mathrm{~g}^{\text {seedling }}{ }^{-1}$, the maximum $Q_{P}, \mathrm{ETR}$, and Yield values were found. While the $\mathrm{N}$ fertilization application increased to $2.0 \mathrm{~g}$ cutting $^{-1}$, the $Q_{P}, \mathrm{ETR}$, and Yield values decreased. Therefore, the exponential $\mathrm{N}$ application is beneficial to the formation of photosynthetic products, but excessive $\mathrm{N}$ application can inhibit electron transport ability.

Table 2. Chlorophyll fluorescence of Chinese fir cuttings under different fertilization levels.

\begin{tabular}{cccc}
\hline Fertilization Treatments & $Q_{\boldsymbol{P}}$ & ETR & Yield \\
\hline CK & $0.79 \pm 0.00 \mathrm{c}$ & $32.53 \pm 0.19 \mathrm{~d}$ & $0.65 \pm 0.00 \mathrm{c}$ \\
CF & $0.88 \pm 0.02 \mathrm{ab}$ & $32.70 \pm 0.37 \mathrm{~d}$ & $0.66 \pm 0.01 \mathrm{bc}$ \\
EF1 & $0.85 \pm 0.012 \mathrm{~b}$ & $33.72 \pm 0.07 \mathrm{c}$ & $0.67 \pm 0.00 \mathrm{~b}$ \\
EF2 & $0.89 \pm 0.10 \mathrm{a}$ & $35.79 \pm 0.16 \mathrm{a}$ & $0.71 \pm 0.00 \mathrm{a}$ \\
EF3 & $0.87 \pm 0.01 \mathrm{ab}$ & $35.13 \pm 0.24 \mathrm{~b}$ & $0.70 \pm 0.01 \mathrm{a}$
\end{tabular}

$Q_{P}$ : The photochemical quenching; ETR: PSII electron transport rate; Yield: photochemical efficiency of PSII. Different letters in the same column indicate significant difference at 0.05 level.

\subsection{Effects of Different Fertilization Levels on Nutrient Contents of Chinese Fir Rooted Cuttings}

Overall, the $\mathrm{N}$ concentration of Chinese fir cutting-seedlings was in the order of leaf $>$ root $>$ stem (Figure 4). For leaves, the $\mathrm{N}$ concentration of CF treatment was $41.1 \%$ higher than control and the $\mathrm{N}$ concentration of EF treatments were $73.6 \%-135.5 \%$ higher than control. The $\mathrm{N}$ concentration of EF3 was significantly higher than for EF1 and EF2. Compared with the control, the N concentration of CF treatment increased by $39.6 \%$, and the EF treatment increased by $22.6 \%-81.4 \%$. The $\mathrm{N}$ concentrations of roots under EF2 and EF3 were significantly higher than that of CF and EF1. Compared with the control, EF2 and EF3 increased significantly, with EF3 more than EF2. 


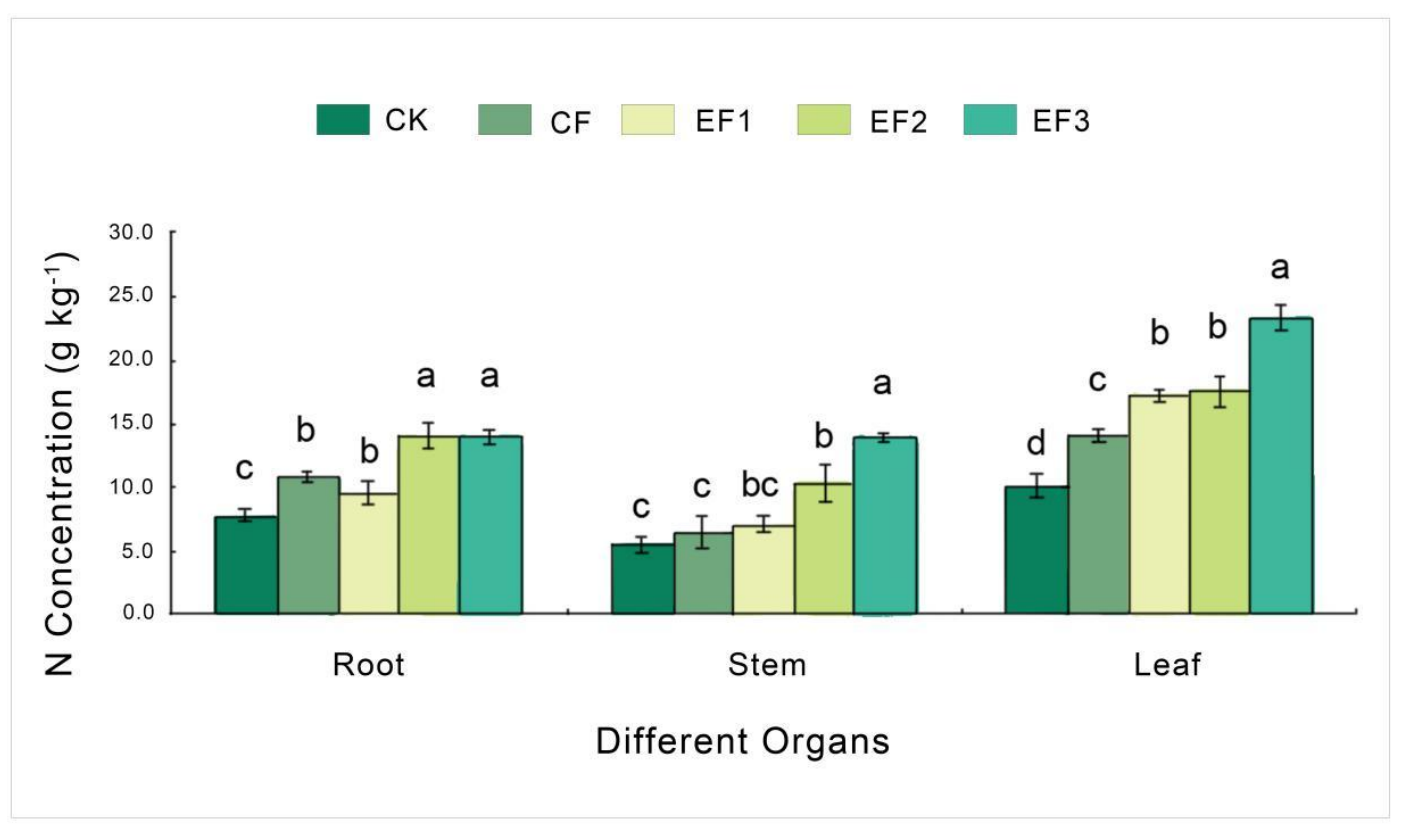

Figure 4. Organ N-concentration of Chinese fir at different fertilization levels. (Different letters in the same histogram of organs indicate significant difference at 0.05 level).

The $\mathrm{P}$ concentrations of the roots and leaves under the four $\mathrm{N}$-fertilization treatments were significantly higher than that of $\mathrm{CK}$, respectively (Figure 5). However, the differences of $\mathrm{P}$ concentrations between $\mathrm{EF}$ and $\mathrm{CF}$ were not significant. For the $\mathrm{P}$ concentrations of the stem, no significant differences were found among treatments. For roots, stems, and leaves of Chinese fir cuttings, no significant differences of $\mathrm{K}$ concentrations under different treatments were observed (Figure 6).

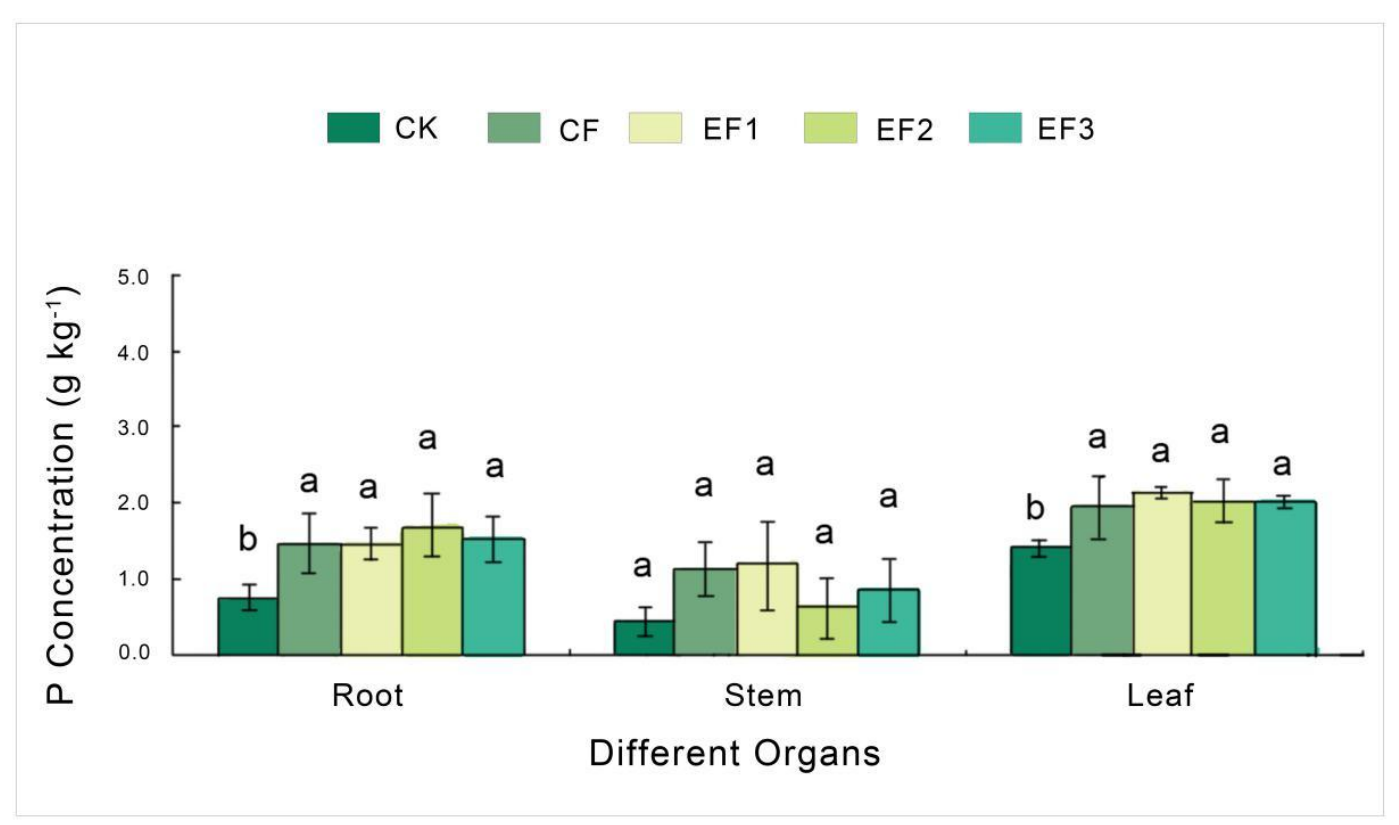

Figure 5. Organ phosphorus (P)-concentration of Chinese fir at different fertilization levels. (Different letters in the same histogram of organs indicate significant difference at 0.05 level). 


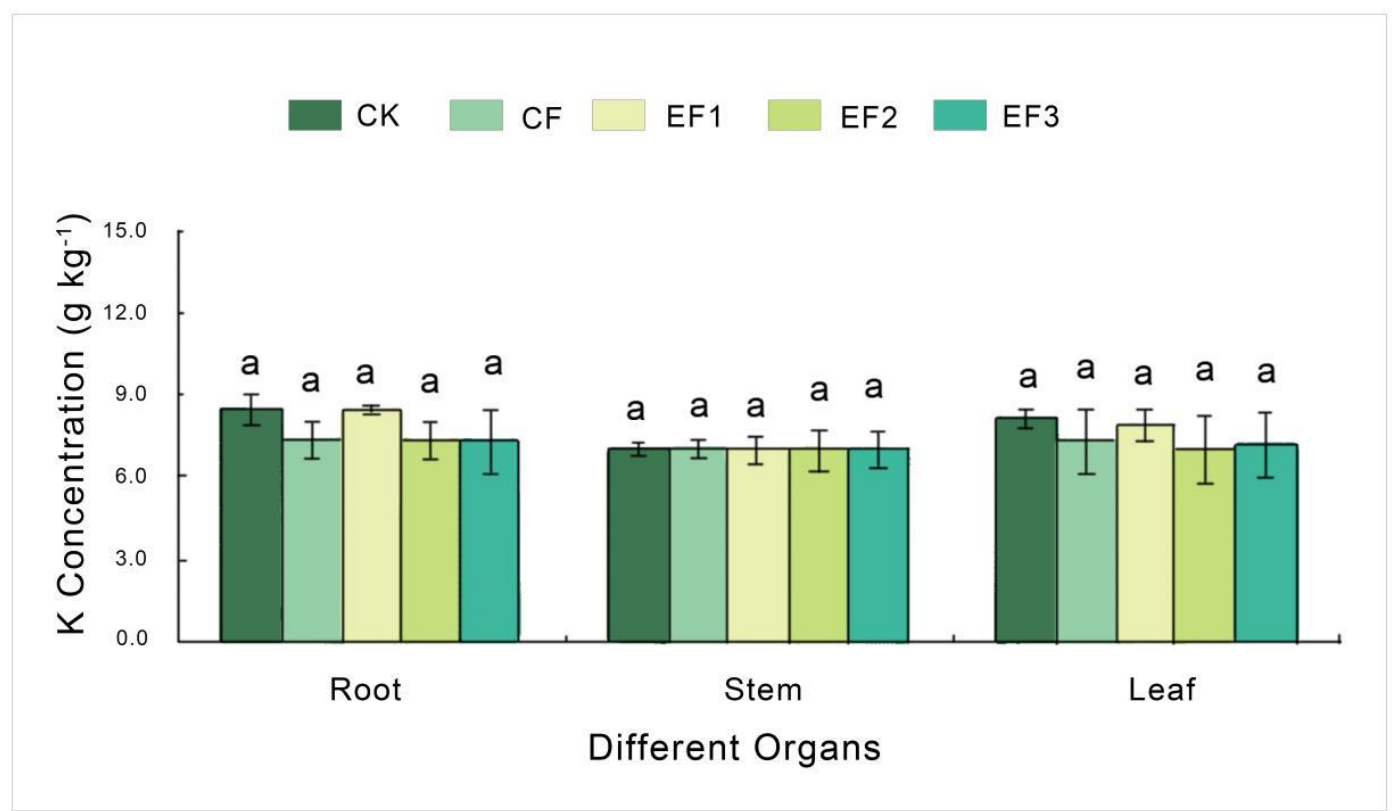

Figure 6. Organ potassium (K)-concentration of Chinese fir at different fertilization levels. (Different letters in the same histogram of organs indicate significant difference at 0.05 level).

\section{Discussion}

Height and ground diameter are important indicators for estimating the quality of seedlings [34]. In this study, the height and ground diameter of fertilized cuttings were significantly higher than those without fertilizer, similar to the results of Aquilaria sinensis (Lour.) Spreng seedlings [35]. The EF2 treatment had the best height and ground diameter, indicating that proper $\mathrm{N}$ application could promote the growth of Chinese fir rooted cuttings, while excessive application of $\mathrm{N}$ could inhibit its growth, which was in line with the effect of exponential fertilization on the rooted cuttings of Catalpa bungei C. A. Mey [23].

Biomass is an important indicator to measure the productivity of seedlings. The biomass allocation in plants is affected by the amount of $\mathrm{N}$ applied. In the exponential fertilization, the root biomass decreased slightly with the increase of $\mathrm{N}$ application rate. This is because when $\mathrm{N}$ is deficient, plants increase the proportion of root biomass to increase the $\mathrm{N}$ uptake capacity of the roots. The biomass of stems, leaves, and whole plants treated with exponential fertilization showed a trend of increasing first and then decreasing with the increase of total $\mathrm{N}$ application rate, indicating that proper fertilization promoted the growth of rooted cuttings [23], significantly increased the accumulation of dry matter in seedlings [14,36], while excessive $\mathrm{N}$ application caused slight poison to seedlings $[15,21,37-40]$, further impeded the seedling growth and biomass accumulation [41,42]. The highest ratio (1.90) of aboveground biomass/belowground biomass at the final harvest occurred with EF2, the lowest (0.76) was attained with the $\mathrm{CK}$, illustrating that ample and stable nutrients supply in the growing medium tended to enhance shoot growth more than root growth [43-45]. While Hawkins et al. [8] found that the seedling height differed, biomass of western hemlock (Tsuga heterophylla (Raf.) Sarg.) did not differ greatly among exponential or constant-rate fertilization treatments in the greenhouse. Boivin et al. [46] indicated that the root growth increased much more than shoot growth during the late season fertilization process. The probability of the above difference could be related to different experimental species and fertilization process.

Photosynthesis is the basis of biomass production of seedling. The chlorophyll fluorescence is a probe for photosynthesis [47], in which $Q_{P}$ reflects the share of photochemical electron transport in the PSII antenna pigment absorption. To a certain extent, $Q_{P}$ reflects the openness of the PSII reaction center. The relative ETR of PSII indicates the ability of a photosynthetic mechanism to absorb light energy, which generates charge separation and electrons that passes down the electron transport chain. Yield 
is the effective quantum yield of photo-chemistry. EF treatments were significantly higher than of the control and CF treatments, and showed a trend of increasing first and then decreasing with the increase of nitrogen application rate. This phenomena indicated that proper nitrogen application improved the photosynthetic performance of Chinese fir leaves, increased the PSII activity and the maximum photochemical efficiency of PSII, increased the openness of the PSII reaction center, and improved the apparent electron transport rate and the total photochemical quantum yield of PSII. The radiant energy is dissipated so that the light absorbed by the leaves is more fully used for photosynthesis [48], but a large amount of $\mathrm{N}$ inhibits the ability of electron transport. Exponential fertilization is beneficial to the formation of photosynthetic products, and the amount of fertilizer applied should be controlled at 1.0 g cutting $^{-1}$.

Fertilization can increase the $\mathrm{N}$ concentration of roots, stems, and leaves of cuttings, and the increase of $\mathrm{N}$ content can promote the growth and competitiveness of cuttings, thus increasing the possibility of successful afforestation. Exponential fertilization significantly increased the $\mathrm{N}$ content of roots, stems, and leaves of Chinese fir cuttings. After 210 days of fertilization, the $\mathrm{N}$ content of roots, stems, and leaves treated with exponential $\mathrm{N}$ application of 1.0 and $2.0 \mathrm{~g}^{\text {cutting }}{ }^{-1}$ was significantly higher than that of $\mathrm{CF}$ and $\mathrm{CK}$, and increased with the increase of $\mathrm{N}$ application rate, which is consistent with the findings in another study [6]. While Timmer et al. [9] and Salifu et al. [10] found that when the nutrient supply is in short or sufficient, the nutrient concentration of seedlings increases with the increase of nutrient supply; when the nutrient supply exceeds the optimal demand for seedlings, the nutrient content will not continue to increase or even decrease. The reason for contradictory results may be related to the test materials and test methods [21].

$\mathrm{P}$ concentration after $\mathrm{N}$-fertilization tended to be higher than without using $\mathrm{N}$-fertilizer, suggesting that $\mathrm{N}$ application was beneficial for accumulation of $\mathrm{P}$ in Chinese fir cuttings. It may be that the supply of $\mathrm{N}$ promotes the growth of Chinese fir cuttings and causes a relative higher demand of $\mathrm{P}$ [49], which increases the $\mathrm{P}$ absorption and the concentration of $\mathrm{P}$ in Chinese fir cuttings after $\mathrm{N}$-fertilizer application. After 210 days of $\mathrm{N}$-fertilization, the differences of $\mathrm{K}$ concentrations in organs among different treatments were not significant, implying that $\mathrm{P}$ and $\mathrm{K}$ had different absorption characteristics by Chinese fir rooted cuttings.

\section{Conclusions}

Fertilization application significantly increased the biomass and nutrient concentration of Chinese fir cuttings. The Chinese fir cuttings with exponential application of $1.0 \mathrm{~g} \mathrm{cutting}^{-1}$ had the highest biomass accumulation and nutrient loading. Considering the growth traits, chlorophyll fluorescence characteristics, $\mathrm{N}, \mathrm{P}$, and $\mathrm{K}$ concentrations of cuttings, the $\mathrm{N}$ application rate of $1.0 \mathrm{~g}$ cutting $^{-1}$ is the critical point to satisfy the growth of Chinese fir rooted cuttings, and can obtain higher biological characteristics of Chinese fir. This can obtain suitable $\mathrm{N}$ application in greenhouse cultivation of Chinese fir rooted cuttings.

Author Contributions: Conceptualization, H.L.; methodology, L.G.; software, J.D.; validation, L.Z.; writing —original draft preparation, J.W.; writing—review and editing, W.F.

Funding: This study was financially supported by the State Key Laboratory of Subtropical Silviculture (20180207), National Natural Science Foundation of China (No. 41201323), and Zhejiang Key Scientific and Technological Innovation Group (No.2009R50033).

Acknowledgments: We thank Huan Liu for her work on soil sampling and analysis.

Conflicts of Interest: The authors declare no conflict of interest.

\section{References}

1. Sun, H.Y.; Liu, Y.; Ma, L.Y.; Jia, Z.K.; Kang, Y.Y.; Jin, H.F.; Jiang, H.; Liu, F.S.; Li, X.L. Effects of supplying of nitrogen phosphorus to Larix olgensis seedling quality. J. Inner Mongolia agri. Univ. 2011, 32, 58-62. (In Chinese) 
2. Hu, Y.L.; Hu, Y.; Zeng, D.H.; Xiao, T.; Chang, S.X. Exponential fertilization and plant competition effects on the growth and $\mathrm{N}$ nutrition of trembling aspen and white spruce seedlings. Can. J. For. Res. 2014, 45, 78-86. [CrossRef]

3. Woods, P.; Nambiar, E.; Smethurst, P. Effect of annual weeds on water and nitrogen availability to Pinus radiata trees in a young plantation. For. Ecol. Manag. 1992, 48, 145-163. [CrossRef]

4. Ervin, D.; Jussaume, R. Integrating social science into managing herbicide-resistant weeds and associated environmental impacts. Weed Sci. 2014, 62, 403-414. [CrossRef]

5. Imo, M.; Timmer, V.R. Growth and nutritional interactions of nutrient-loaded black spruce seedlings with neighboring natural vegetation under greenhouse conditions. For. Sci. 2002, 48, 77-84.

6. Malik, V.; Timmer, V.R. Interaction of nutrient-loaded black spruce seedlings with neighbouring vegetation in greenhouse environments. Can. J. For. Res. 1995, 25, 1017-1023. [CrossRef]

7. Oliet, J.A.; Planelles, R.; Aptero, F.; Valverde, R.; Jacobs, D.; Segura, M.L. Field performance of Pinus halepensis planted in Mediterranean arid condition: Relative influence of seeding morphology and mineral nutrition. New For. 2009, 37, 313-331. [CrossRef]

8. Hawkins, B.J.; Burgess, D.; Mitchell, A.K. Growth and nutrient dynamics of western hemlock with conventional or exponential greenhouse fertilization and planting in different fertility conditions. Can. J. For. Res. 2005, 35, 1002-1016. [CrossRef]

9. Timmer, V.R. Exponential nutrient loading: A new fertilization technique to improve seedlings performance on competitive sites. New For. 1996, 13, 275-295.

10. Salifu, K.F.; Jacobs, D.F.; Birge, Z.K. Nursery nitrogen loading improves field performance of bare root oak seedlings planted on abandoned mine lands. Restor. Ecol. 2009, 17, 339-349. [CrossRef]

11. Li, Y.F.; Hu, S.D.; Chen, J.H.; Muller, K.; Li, Y.C.; Fu, W.J.; Lin, Z.W.; Wang, H.L. Effects of biochar application in forest ecosystems on soil properties and greenhouse gas emission: A review. J. Soils Sediments 2018, 18, 546-563. [CrossRef]

12. Fu, W.J.; Fu, Z.J.; Ge, H.L.; Ji, B.Y.; Jiang, P.K.; Li, Y.F.; Wu, J.S.; Zhao, K.L. Spatial variation of biomass carbon density in a subtropical region of southeastern China. Forests 2015, 6, 1966-1981. [CrossRef]

13. Wei, H.X.; Xu, C.Y.; Ma, L.Y.; Jiang, L.N. Advances in Study on Seedling Exponential Fertilization Regime. Sci. Silvae Sinicae 2010, 46, 140-146. (In Chinese)

14. Malik, V.; Timmer, V.R. Biomass partitioning and nitrogen retranslocation in black spruce seedlings on competitive mixed wood sites: A bioassay study. Can. J. For. Res. 1998, 28, 206-215. [CrossRef]

15. Salifu, K.F.; Timmer, V.R. Nitrogen retranslocation response of young Picea mariana to nitrogen-15 supply. Soil Sci. Soc. Am. J. 2003, 67, 309-318.

16. McAlister, J.A.; Timmer, V.R. Nutrient enrichment of white spruce seedlings during nursery culture and initial plantation establishment. Tree Physiol. 1998, 18, 195-202. [CrossRef] [PubMed]

17. Fu, W.J.; Fu, Z.J.; Zhao, K.L.; Tunney, H.; Zhang, C.S. Variation of soil $\mathrm{P}$ and other nutrients in a long-term grazed grassland P experiment field. Arch. Agron. Soil Sci. 2014, 60, 1459-1466. [CrossRef]

18. Everett, K.T.; Hawkins, B.J.; Kiiskila, S. Growth and nutrient dynamics of Douglas-fir seedlings raised with exponential or conventional fertilization and planted with or without fertilizer. Can. J. For. Res. 2007, 37, 2552-2562. [CrossRef]

19. Jia, H.J.; Ingestad, T.A. Study on optimum nutrient trqurements of Paulownia elongata and Robinia pseudoacacia seedlings. Sci. Silvae Sin. 1989, 25, 1-6. (In Chinese)

20. Dai, W.; Fu, W.J.; Jiang, P.K.; Zhao, K.L.; Li, Y.H.; Tao, J.X. Spatial pattern of carbon stocks in forest ecosystems of a typical subtropical region of southeastern China. Forest Ecol. Mang. 2018, 409, 288-297. [CrossRef]

21. Yu, Z.Y.; Dong, J.Q.; Fu, W.J.; Ye, Z.Q.; Li, W.Y.; Zhao, K.L. The transfer characteristics of potentially toxic trace elements in different soil-rice systems and their quantitative models in southeastern China. Int. J. Environ. Res. Public Health 2019, 16, 2503. [CrossRef]

22. Fang, X.H.; Zhang, J.C.; Meng, M.J.; Guo, X.P.; Wu, W.Y.; Liu, X.M.; Zhao, K.L.; Ding, L.Z.; Shao, Y.F.; $\mathrm{Fu}$, W.J. Forest-type shift and subsequent intensive management affected soil organic carbon and microbial community in southeastern China. Eur. J. For. Res. 2017, 136, 689-697. [CrossRef]

23. Wang, L.P.; Yan, Z.Y.; Li, J.Y.; Wang, J.H.; He, X.; Su, Y.; Chen, B.; Ma, J.W.; Dong, J.L. Effects of exponential fertilization on biomass allocation and root morphology of Catalpa bungei clones. Acta Ecol. Sin. 2012, 32, 7452-7462. (In Chinese) [CrossRef] 
24. Chen, Q.T. Comparison test and repeatability estimates on Cunninghamia lanceolata clones afforestation. For. Inventory Plann 2012, 35, 140-144. (In Chinese)

25. Wu., W.F.; Lin, H.P.; Fu, W.J.; Penttinen, P.; Li, Y.F.; Jin, J.; Zhao, K.L.; Wu, J.S. Soil organic carbon content and microbial functional diversity were lower in monospecific Chinese hickory stands than in natural Chinese hickory-broad-leaved mixed forests. Forests 2019, 10, 357. [CrossRef]

26. Fu, W.J.; Jiang, P.K.; Zhao, K.L.; Zhou, G.M.; Li, Y.F.; Wu, J.S.; Du, H.Q. The carbon storage in Moso Bamboo plantation and its spatial variation in Anji County of southeastern China. J. Soils Sediments 2014, 14, 320-329. [CrossRef]

27. World Reference Base for Soil Resources (WRB). A Framework for International Classification, Correlation and Communication; Food and Agriculture Organization of the United Nations: Rome, Italy, 2006.

28. Ingestad, T.; Lund, A. Nitrogen stress in birch seedling: Growth technique and growth. Physiol. Plant. 1979, 45, 137-148. [CrossRef]

29. Fu, W.J.; Zhao, K.L.; Zhang, C.S.; Wu, J.S.; Tunney, H. Outlier identification of soil phosphorus and its implication for spatial structure modeling. Precis. Agric. 2016, 17, 121-135. [CrossRef]

30. Zhao, K.L.; Fu, W.J.; Qiu, Q.Z.; Ye, Z.Q.; Li, Y.F.; Tunney, H.; Dou, C.Y.; Zhou, K.N.; Qian, X.B. Spatial patterns of potentially hazardous metals in paddy soils in a typical electrical waste dismantling area and their pollution characteristics. Geoderma 2019, 337, 453-462. [CrossRef]

31. Fu, W.J.; Tunney, H.; Zhang, C.S. Spatial variation of soil nutrients in a dairy farm and its implications for site-specific fertilizer application. Soil Till. Res. 2010, 106, 185-193. [CrossRef]

32. Dai, W.; Zhao, K.L.; Fu, W.J.; Jiang, P.K.; Li, Y.F.; Zhang, C.S.; Gielen, G.; Gong, X.; Li, Y.H.; Wang, H.L.; et al. Spatial variation of organic carbon density in topsoils of a typical subtropical forest, southeastern China. Catena 2018, 167, 181-189. [CrossRef]

33. Fu, W.J.; Zhao, K.L.; Tunney, H.; Zhang, C.S. Using Moran's I and geostatistics to identify spatial patterns of soil nutrients in two different long-term phosphorus application plots. J. Plant Nutr. Soil Sci. 2011, 174, 785-798. [CrossRef]

34. Wang, R.; Li, J.Y.; Zhang, F.Q.; Zhu, B.Z.; Pan, W. Growing dynamic root system of Aquilaria malaccensis and Aquilaria sinensis seedlings in response to different fertilizing methods. Acta Ecol. Sin. 2011, 31, 98-106. (In Chinese)

35. Hao, L.F.; Wang, Q.C.; Zhang, Y.D.; Xu, Q.X.; Peng, H.M.; Liu, T.Y. Effect of exponential fertilization on biomass and nutrient dynamics of Padus maackii seedlings. Sci. Silv. Sin. 2012, 48, 33-39. (In Chinese)

36. Liu, Z.H.; Liu, Y.; Duan, S.S. Effects of fertilization methods on seedling growth and drought tolerance of Platycladus orientalisunder different water conditions. J. Beijing For. Univ. 2002, 24, 56-60. (In Chinese)

37. Dai, W.; Li, Y.; Fu, W.; Jiang, P.; Zhao, K.; Li, Y.; Penttinen, P. Spatial variability of soil nutrients in forest areas: A case study from subtropical China. J. Plant Nutr. Soil Sci. 2018, 181, 827-835. [CrossRef]

38. Fu, W.J.; Zhao, K.L.; Zhang, C.S.; Tunney, H. Using GIS and geostatistics to optimize soil phosphor and magnesium sampling in temperate grassland. Soil Sci. 2013, 178, 240-247. [CrossRef]

39. Fu, W.J.; Jiang, P.K.; Zhou, G.M.; Zhao, K.L. Using Moran's I and GIS to study spatial pattern of forest litter carbon density in typical subtropical region, China. Biogeosciences 2014, 11, 2401-2409. [CrossRef]

40. Yu, S.Y.; Chen, Z.L.; Zhao, K.L.; Ye, Z.Q.; Zhang, L.Y.; Dong, J.Q.; Shao, Y.F.; Zhang, C.S.; Fu, W.J. Spatial Patterns of Potentially Hazardous Metals in Soils of Lin'an City, Southeastern China. Int. J. Environ. Res. Public Health 2019, 16, 246. [CrossRef]

41. Wen, G.S.; Tian, H.T.; Zhang, M.R.; Jiang, W.W. Application of chlorophyll fluorescence analysis in forest tree cultivation. Chin. J. Appl. Ecol. 2006, 17, 1973-1977. (In Chinese)

42. Zhao, K.L.; Fu, W.J.; Ye, Z.Q.; Zhang, C.S. Contamination and spatial variation of heavy metals in the soil-rice system in Nanxun county, southeastern China. Int. J. Environ. Res. Public Health 2015, 12, 1577-1594. [CrossRef] [PubMed]

43. Xu, X.J.; Timmer, V.R. Biomass and nutrient dynamics of Chinese fir seedlings under conventional and exponential fertilization regimes. Plant Soil 1998, 203, 313-322. [CrossRef]

44. Timmer, V.R.; Armstrong, G. Growth and nutrition of Pinus resinosa seedlings at exponentially increasing nutrient additions. Can. J. For. Res. 1987, 17, 644-647. [CrossRef]

45. Timmer, V.R.; Munson, A.D. Site-specific growth and nutrient uptake of planted Picea mariana in the Ontario Clay Belt. IV. Nitrogen loading response. Can. J. For. Res. 1991, 21, 1058-1065. [CrossRef] 
46. Boivin, J.R.; Miller, B.D.; Timmer, V.R. Later season fertilization of Picea mariana seedlings under greenhouse culture: Biomass and nutrient dynamics. Ann. For. Sci. 2002, 59, 255-264. [CrossRef]

47. Zhang, W.F.; Gou, L.; Wang, Z.L.; Li, S.K.; Yu, S.L.; Cao, L.P. Effect of nitrogen on chlorophyll fluorescence of leaves of high-yielding cotton in Xinjiang. Sci. Agric. Sin. 2003, 36, 893-898. (In Chinese)

48. Xu, J.K.; Chen, W.; Wang, J.; Fei, X.H. Effects of different fertilization strategies on growth and nutrition characteristics of Machilus thunbergii. Chin. J. Ecol. 2015, 34, 1241-1245. (In Chinese)

49. Salifu, K.F.; Timmet, V. Optimizing nitrogen loading of Picea mariana seedlings during nursery culture. Can. J. For. Res. 2003, 33, 1287-1294. [CrossRef]

(C) 2019 by the authors. Licensee MDPI, Basel, Switzerland. This article is an open access article distributed under the terms and conditions of the Creative Commons Attribution (CC BY) license (http://creativecommons.org/licenses/by/4.0/). 